isoenzymes in human tissues. Ann. Hum. Genet., 35: 207 (1971).

5. Giblett, E. E., Anderson, J. E., Cohen, F., Pollara, B., and Meuwissen, H. J. Adenosine-deaminase deficiency in two patients with severely impaired cellular immunity. Lancet, $i i: 1067$ (1972).

6. Goldberg, D. M.: Serum adenosine deaminase in the differential diagnosis of jaundice. Brit. Med. J., i: 353 (1965)

7. Good, R. A., Peterson, R. D. A., Finstad, J., and Gabrielsen, A. E.: Ser Haematol., 8: 1 (1965).

8. Green, H., and Chan, T.-S.: Pyrimidine starvation induced by adenosine in fibroblasts and lymphoid cells: Role of adenosine deaminase. Science, 182: 836 (1973).

9. Green, H., and Ishii, K.: On the existence of a guanine nucleotide trap: The role of adenosine kinase and a possible cause of excessive purine production in mammalian cells. J. Cell. Sci., ii: 173 (1972)

10. Hirschhorn, R., and Levytska, V.: Alterations in isozymes of adenosine deaminase during stimulation of human peripheral blood lymphocytes. Cell Immunol., 12: 387 (1974)

11. Hirschhorn, R., Levytska, V., Pollara, B., and Meuwissen, H.: Evidence for control of several different tissue-specific isozymes of adenosine-deaminase by a single genetic locus. Nature New Biol., 246: 200 (1973).

12. Hitzig, W. H., Biro, Z., Bosch, H., and Huser, H. J.: Agammaglobulinämie und Alymphozytose mit Schwund des lymphatischen Gewebes. Helv. Paediat. Acta, 13: 551 (1958).

13. Hitzig, W. H., Barandun, S., and Cottier, H.: Die Schweizerische Form der Agammaglobulinämie. Ergebn. Inn. Med. Kinderheilk., 27: 79 (1968)

14. Hitzig, W. H., Landolt, R., Müller, G., and Bodmer, P.: Heterogeneity of phenotypic expression in a family with Swiss-type agamma-globulinemia: Observations on the acquisition of agamma-globulinemia. J. Pediat., 78: 968 (1971).

15. Hopkinson, D. A., Cook, P. J. L., and Harris, H.: Further data on the adenosine deaminase (ADA) polymorphism and a report of a new phenotype. Ann. Hum. Genet., 32: 361 (1969)

16. Ishii, K., and Green, H.: Lethality of adenosine for cultured mammalian cells by interference with pyrimidine biosynthesis. J. Cell. Sci., 13: 429 (1973)

17. Jenkins, $\Upsilon$.: Red-blood-cell adenosine deaminase deficiency in a "healthy"!Kung individual. Lancet, ii: 736 (1973).

18. Katckar, H. M.: Differential spectrophotometry of purine compounds by means of specific enzymes. III. Studies of the enzymes of purine metabolism. J. Biol. Chem., 167: 461 (1974)

19. Meuwissen, H. J., Pickering, R. J., Moore, R. E., and Pollara, B.: Impairment of adenosine deaminase activity in combined immunological deficiency disease. (Submitted for publication).
20. Meuwissen, H. J., and Pollara, B.: Adenosine deaminase deficiency: The first inborn error of metabolism noted in immunodeficiency disease. $J$. Pediat., 84 : 315 (1974).

21. Meuwissen, H. J., Pollara, B., and Pickering, R. J.: Combined immunodeficiency disease associated with adenosine deaminase deficiency. J. Pediat., 86: 169 (1975).

22. Murray, A. W.: The biological significance of purine salvage. Ann. Rev. Biochem., 40: 811 (1971).

23. Nézelof, C., Jammet, M. L., Lortholary, P., Labrune, B., and Lamy, M. L'hypoplasie héréditaire du thymus. Arch. franç. Pédiat., 21: 897 (1964).

24. Pollara, B., and Meuwissen, H. J.: Combined immunodeficiency disease and ADA-deficiency. Lancet, ii: 1324 (1973).

25. Pollara, B., Pickering, R. J., and Meuwissen, H. J.: Combined immunodeficiency disease and adenosine deaminase deficiency: An inborn error of metabolism. Pediat. Res., 7: 362 (1973).

26. Schwenk, H. U., Gimpert, E., Plüss, H. J., Pilgrim, U., and Hitzig, W. H.: Lymphocyte markers for B- and $\mathrm{T}$-cells in primary immunodeficiency disease. Klin. Wschr., 52: 426 (1974).

27. Scott, C. R., Chen, S.-H., and Giblett, E. R.: Detection of the carrier state in combined immunodeficiency disease associated with adenosine deaminase deficiency. J. Clin. Invest., 53: 1194 (1974).

28. Tobler, R., and Cottier, H.: Familiäre Lymphopenie mit Agamma-globulinämie und schwerer Moniliasis-Die "essentielle Lymphocytophthise" als besondere Form der frühkindlichen Agammaglobulinämie. Helv. Paediat. Acta, 13: 313 (1958)

29. Van der Weyden, M. B., Buckley, R. H., and Kelley, W. N.: Molecular form of adenosine deaminase in severe combined immunodeficiency. Biochem. Biophys. Res. Commun., 57: 590 (1974).

30. Wolberg, G., Zimmermann, T. P., Hiemstra, K., Winston, M., and Chu, L.-C. Adenosine inhibition of lymphocyte-mediated cytolysis: Possible role of cyclic adenosine monophosphate. Science, 187: 957 (1975)

31. Yount, J., Nichols, P., Ochs, H. D., Hammar, S. P., Scott, R., Chan, S.-H., Giblett, E. R., and Wedgwood, R. J.: Absence of erythrocyte adenosine deaminase associated with severe combined immunodeficiency. J. Pediat., 84: 173 (1974).

32. We thank Dr. Dooren, Department of Pediatrics, University of Leiden, Holland, for these data, obtained at the Central Laboratory of the Dutch Red Cross, Amsterdam.

33. This research was supported by Schweiz Nationalfonds Grant no. 2.8820 .72

34. Requests for reprints should be addressed to: W. H. Hitzig, M.D., Kinderspital, 8032 Zürich (Switzerland)

35. Accepted for publication September 15, 1975

Copyright @ 1976 International Pediatric Research Foundation, Inc.

Printed in U.S.A.

Pediat. Res. 10: 70-75 (1976)

Brain development cytochrome oxidase inorganic lead mitochondria

NAD-linked respiration

oxidative phosphorylation

\title{
Early Effects of Inorganic Lead on Immature Rat Brain Mitochondrial Respiration
}

\author{
D. HOLTZMAN('(4) AND J. SHEN HSU \\ Departments of Neurology and Pediatrics, Stanford University School of Medicine, Stanford, California, USA
}

\section{Extract}

Inorganic lead, added to the diet of the suckling rat in high doses, produces an encephalopathy similar to that seen in the immature human. Pathologic changes of edema and hemorrhage are seen earliest and are most prominent in the cerebellum. In this study, we measured respiration in cerebral hemisphere and cerebellar mitochondria isolated from led-fed and age-matched normal rat pups. Lactating mothers were begun on ad libitum feedings containing 4\% lead carbonate when their pups were 2 weeks old. Mitchondria were isolated by differential centrifugation. Oxygen consumption was measured polarographically. NAD-linked respiration was measured with oxidation of the substrate pair, glutamate and malate. Cytochrome oxidase (cytochrome $c$ oxidase, EC. 1.9.3.1) activity was measured in the presence of tetramethyl- $p$-phenylenediamine dihydrochloride (TMPD) and ascorbate. Within 2 days of starting lead feedings, rat pups showed a significant loss in body weight $(P$ $<0.02$ ) and, after 1 week, a significant loss in cerebral hemisphere wet weight $(P<\mathbf{0 . 0 1})$ compared with controls. Overt encephalopathy appeared in pups from two of nine litters receiving lead feedings for 1 week and in half of the litters after 2 weeks of feedings. None of the lead-fed mothers developed encephalopathic signs. With oxidation of the NAD-linked substrate pair, there was a progressive decrease, relative to controls, in $\mathrm{ADP} / \mathrm{O}$ ratios in both cerebellar 
and cerebral mitochrondria from lead-fed animals. After 2 weeks these differences were significant in mitochondria from both regions (cerebellum, $P<\mathbf{0 . 0 2}$; cerebrum, $P<\mathbf{0 . 0 0 5}$ ). Respiratory control ratios were significantly lower in cerebellar mitochondria from lead-fed rats within 2 days of beginning feedings $(P<0.02)$ and in mitochondria from both regions after 2 weeks of lead feedings (cerebellum, $P<0.01$; cerebrum, $P<0.05$ ). The decrease in control ratios in cerebellar mitochondria from animals receiving lead feedings for 1 week or less was due to a small decrease in state 3 respiration and a large, but inconsistent, increase in state 4 respiration. The decrease in control ratios in both cerebellar and cerebral hemisphere mitochondria after 2 weeks of lead feedings was due to a marked inhibition of state 3 respiration, relative to controls (cerebellum, $P<\mathbf{0 . 0 1}$; cerebral hemisphere, $P<0.05$ ). In cerebellar mitochondria from lead-fed animals, cytochrome oxidase activity showed similar changes compared with controls: a highly significant $(P<\mathbf{0 . 0 0 1})$ increase within 2 days of beginning feedings and a significant $(P<0.01)$ decrease after 2 weeks of feedings.

\section{Speculation}

The effects of inorganic lead feedings were greater in mitochondria from cerebellum than from cerebral hemispheres. The changes in respiratory chain function, which appeared sooner after beginning lead feedings than any previously reported biochemical or morphologic effect on rat cerebellum, may constitute an early step in the pathogenesis of an encephalopathy which is predominant in this region of the suckling rat brain. In cerebellar mitochondria, inorganic lead may be acting as an uncoupling agent, such as dinitrophenol, affecting both NAD-linked respiration and cytochrome oxidase activity. The maturing brain may be most sensitive to the encephalopathic effects of lead at a critical period of rapid synthesis and increasing activity of respiratory enzymes. The greater effects on cerebellar mitochondria may be related to regional differences in mitochondria respiratory chain properties during this maturational period.

Inorganic lead, added in large doses to the diet of the suckling rat, produces an encephalopathy similar to that seen in the immature human $(6,27,32)$. The encephalopathy, manifested by obtundation and paraparesis, appears in the 4 th or 5 th week of life, if lead exposure is begun by 2 weeks. The mature rat brain, like that of the mature human, is not sensitive to these effects of inorganic lead. In the rat pups, pathologic changes of edema and hemorrhage are most prominent in the cerebellum and basal ganglia, but white matter edema does appear in the cerebral hemispheres (6). When the earliest signs of encephalopathy appear, chemical evidence of edema has been shown only in the cerebellum (11). An increase in capillary permeability has been demonstrated in many regions of the central nervous system at this stage (27). The regional edema and increase in capillary permeability have been interpreted as being secondary to a primary capillary endothelial cell dysfunction (11) or to a dysfunction in parenchymal cellular energy metabolism which may affect, either directly or indirectly, properties of the capillary endothelium (27). Recent studies suggest that inorganic lead feedings result in a retardation in maturation of brain glucose metabolism and metabolic compartmentation $(25,26)$.

We have studied respiratory chain function in cerebral hemisphere and cerebellar mitochondria isolated from lead-fed and age-matched normal rat pups. The rationale for study of the respiratory chain as the possible site of action of inorganic lead on the immature brain was based on the following observations. First, in other tissues, the primary effect of inorganic lead appears to be on oxidative phosphorylation $(8,13,29,31)$. Second, in mature rodent brains, organic lead compounds have been shown to affect glucose and oxygen consumption (2) and to decrease cerebellar and cerebral concentrations of the cytochrome heavy metal cofactors: copper, zinc, and iron (23). Third, the period of sensitivity to inorganic lead is that in which the concentrations and activities of respiratory enzymes are rapidly increasing in the developing brain $(14,16,17,28,33)$

\section{MATERIALS AND METHODS}

Sprague-Dawley albino rats of both sexes were used. Pregnant females arrived before the end of gestation to allow accurate age-matching of experimental and control litters. Litters were reduced to eight pups on the first day of life and maintained in one room with one litter and mother per cage. When litters were 2 weeks old, mothers were begun on ad libitum feedings of powdered laboratory chow (34) containing 4\% lead carbonate. This chow is comparable with the common laboratory rat pellets, containing calcium $1.0 \%$, phosphorus $0.74 \%$ and vitamin D $3.3 \mathrm{lU} / \mathrm{g}$. Control animals received powdered chow without the added lead. Pups also has free access to the powdered chows. All feedings were prepared by the laboratory staff.

Mitochondria were isolated from the cerebral hemispheres and cerebellum by differential centrifugation as described in previous publications $(15,22)$. After decapitation the brain was immersed in ice-cold isolation medium consisting of $225 \mathrm{mM}$ mannitol, $75 \mathrm{mM}$ sucrose, $0.2 \mathrm{mM}$ EDTA, $5.0 \mathrm{mM}$ Tris- $\mathrm{HCl}$ ( $\mathrm{pH} \mathrm{7.4).} \mathrm{Cerebral}$ hemispheres and cerebellums were separated and pooled from whole litters at 2 weeks of age and from two to four animals at older ages. The cerebral hemispheres were separated by cutting the peduncles above the mesencephalon. The tissues were then homogenized and $0.1 \mathrm{mg}$ bacillus proteinase, $1 \mathrm{mg}$ bovine serum albumin (BSA), and $1 \mathrm{mg} \mathrm{KHCO}_{3}$ were added for each gram of brain tissue. This mixture was allowed to stand for $2 \mathrm{~min}$ before the centrifugation steps (15). The myelin layer overlying the final mitochondrial pellet was removed by hand and the pellet was washed and resuspended in a small volume of medium without EDTA. An aliquot of this suspension was frozen for protein determination (20).

Oxygen consumption was measured polarographically using the Gilson oxygraph with a $2-\mathrm{ml}$ reaction chamber and Clarke platinum electrode polarized to $0.8 \mathrm{~V}(10)$. The system was calibrated for $\mathrm{O}_{2}$ content as described previously (15). Chamber temperature was maintained at $20^{\circ}$. ADP concentrations were measured biweekly (1). All studies were performed on freshly isolated mitochondria and were completed within $3 \mathrm{hr}$.

NAD-linked respiration was measured with oxidation of an excess of the substrate pair, glutamate and malate $(1.25 \mathrm{mM}$ each). Respiratory rates were measured in the presence of a limiting quantity of ADP, state 3 respiration, and after consumption of the added ADP, state 4 respiration (4). The respiratory control ratio was defined as the ratio of state 3 to state 4 rates (4). ADP/O ratios were calculated by the usual method (5).

Cytochrome oxidase (cytochrome $c$ oxidase, EC 1.9.3.1) activity was measured in the presence ot TMPD $(100 \mu \mathrm{M})$ and ascorbate (1 $\mathrm{mM})$ with antimycin $\mathrm{A}(5 \mu \mathrm{g} / \mathrm{ml})$ in the reaction mixture $(30)$. Rates were determined with and without ADP, but measurable control ratios were not usually obtained, as noted by other investigators for the polarographic assay of cytochrome oxidase (30). The rates presented here are those measured in the absence of added ADP.

The results obtained with mitochondria from lead-fed animals were compared with those from age-matched control animals as matched samples. Mitochondrial samples were isolated from control and experimental litters at the same time. The significance of the difference of the mean results with matched samples compared with zero was calculated by the standard $t$-test for nonindependent samples (7).

\section{CHEMICALS}

Mannitol, sucrose, EDTA, Trizma base, ADP, substrates, and the bacillus proteinase were obtained from Sigma Chemical Co. (35). Defatted BSA was obtained from Miles Laboratories (36), 
Table 1. Brain and body weights of lead-fed and control rats ${ }^{1}$

\begin{tabular}{|c|c|c|c|c|}
\hline \multirow{2}{*}{$\begin{array}{l}\text { Age, } \\
\text { days }\end{array}$} & \multicolumn{2}{|c|}{ Body weight, $g$} & \multicolumn{2}{|c|}{ Cerebral hemisphere weight, $\mathrm{g}$} \\
\hline & Control & Lead & Control & Lead \\
\hline \multirow[t]{2}{*}{15} & $41.47 \pm 1.64$ & $35.59 \pm 1.05$ & $1.06 \pm 0.01$ & $1.01 \pm 0.02$ \\
\hline & \multicolumn{2}{|c|}{$P<0.02$} & \multicolumn{2}{|c|}{$P<0.1$} \\
\hline 21 & \multicolumn{2}{|c|}{$P<0.001$} & $\begin{array}{r}1.06 \pm 0.01 \\
P\end{array}$ & $\begin{array}{l}0.99 \pm 0.01 \\
0.01\end{array}$ \\
\hline 28 & $\begin{array}{r}84.17 \pm 2.85 \\
P\end{array}$ & $\begin{array}{l}39.22 \pm 2.90 \\
.001\end{array}$ & $P<0.005$ & $\begin{array}{l}0.97 \pm 0.02 \\
.005\end{array}$ \\
\hline
\end{tabular}

${ }^{1}$ Each result is the mean \pm SEM body or cerebral hemisphere wet weight of rats from at least nine litters. Experimental animals were fed $4 \%$ lead carbonate from 2 weeks of age and compared with normal, age-matched control litters. $P$ values, for the significance of the mean difference between results with matched litters, were calculated by the standard $t$-test for nonindependent samples.

ascorbate from J. T. Baker Chemical (37), TMPD from Eastman Kodak (38), and antimycin A from CalBiochem (39). All inorganic chemicals were reagent grade.

\section{RESULTS}

Table 1 shows the effects of maternal inorganic lead feedings on body weight and cerebral hemisphere wet weight in the suckling rat. Within 2 days, the pups showed a significant loss in body weight compared with controls. None of these animals appeared to be sick. After 1 and 2 weeks of lead feedings, mean losses in body and brain weight were highly significant. Pups from two of nine litters receiving lead feedings for 1 week developed the encephalopathy, manifested by paretic hind legs and hemorrhagic cerebellums. After 2 weeks of feedings, pups from half of the litters were affected. None of the lead-fed mothers developed any encephalopathic signs.

ADP/O ratios, measured in isolated cerebral hemisphere and cerebellar mitochondria with oxidation of glutamate and malate, are shown in Table 2. Cerebral hemisphere mitochondria from control animals showed the age-dependent increase in ADP/O ratios reported previously for this age period (16), whereas cerebral hemisphere mitochondria from lead-fed animals did not. As in this earlier study (16), cerebellar mitochondria did not show this age-dependent increase in ADP/O ratios after 2 weeks of age. During the period of lead feedings, there was a progressive decrease in ADP/O ratios in cerebellar mitochondria from lead-fed animals. After 2 weeks, the difference between lead-fed and control animals was significant in mitochondria from both brain regions. The degree of significance was greater than shown in Table 2, since, if no clear state 3-4 transition occurred, ADP/O ratios could not be measured and were excluded. This degree of uncoupling of respiratory control was found in 2 of 11 experiments at 3 weeks and 2 of 7 experiments at 4 weeks of age with cerebellar mitochondria from lead-fed animals. One of 7 experiments with cerebral hemisphere mitochondria from 4-week-old lead-fed animals showed complete loss of respiratory control.

The effects of lead feedings on respiratory control ratios with oxidation of glutamate and malate are shown in Figure 1. The range of mean control ratios in both cerebral hemisphere and cerebellar mitochondria from normal animals was 3.5-5.0. As in previous studies $(16,17)$, these values did not change as a function of age in either brain region. Control ratios were significantly lower in cerebellar mitochondria from experimental animals within 2 days of beginning lead feedings. After 2 weeks of lead feedings, control ratios were significantly lower in both cerebral and cerebellar mitochondria.

Mean state 3 and state 4 respiratory rates, which comprise the respiratory control ratio, are shown in Figure 2 for cerebellar mitochondria. The decrease in respiratory control ratios in cerebellar mitochondria from animals receiving lead feedings for 1 week or less was due to a small decrease in state 3 respiration and a large, but inconsistent, increase in state 4 respiration. The significant decrease in control ratios in these mitochondria after 2 weeks of lead feedings was due to a marked inhibition of state 3 respiration compared with controls. Cerebral hemisphere mitochondria from lead-fed animals showed no change in state 4 rates. These mitochondria did show a relative decrease in state 3 respiration which was similar to, but less significant $(P<0.05)$ than, that seen in cerebellar mitochondria. The age-dependent increase in state 3 respiration, observed in normal rat cerebral

Table 2. ADP/O ratios with oxidation of glutamate and malate in brain mitochondria from lead-fed and control rats ${ }^{1}$

\begin{tabular}{|c|c|c|c|c|}
\hline \multirow{2}{*}{$\begin{array}{l}\text { Age, } \\
\text { days }\end{array}$} & \multicolumn{2}{|c|}{ Cerebral hemispheres } & \multicolumn{2}{|c|}{ Cerebellum } \\
\hline & Controls & Lead & Controls & Lead \\
\hline \multirow[t]{2}{*}{15} & $2.06 \pm 0.14$ & $2.11 \pm 0.19$ & $2.37 \pm 0.17$ & $2.12 \pm 0.13$ \\
\hline & \multicolumn{2}{|c|}{$P>0.9$} & \multicolumn{2}{|c|}{$P<0.25$} \\
\hline 21 & $\begin{array}{r}2.38 \pm 0.10 \\
P\end{array}$ & $\begin{array}{l}2.21 \pm 0.08 \\
0.2\end{array}$ & $\begin{array}{r}2.20 \pm 0.11 \\
P\end{array}$ & $\begin{array}{l}2.08 \pm 0.12^{2} \\
0.2\end{array}$ \\
\hline 28 & $P<0.005$ & $\begin{array}{l}2.14 \pm 0.12^{3} \\
.005\end{array}$ & $\begin{array}{r}2.27 \pm 0.17 \\
P\end{array}$ & $P<0.02$ \\
\hline
\end{tabular}

${ }^{1}$ Oxygen consumption was measured polarographically after adding $0.15-0.25 \mu \mathrm{mol}$ ADP to the reaction mixture containing $1.25 \mathrm{mM}$ each of glutamate and malate, fresh bovine serum albumin $0.2 \mathrm{mg} / \mathrm{ml}$, mannitol $225 \mathrm{mM}$, sucrose $75 \mathrm{mM}$, EDTA $0.2 \mathrm{mM}$, Tris- $\mathrm{HCl}$ (pH 7.4) $5.0 \mathrm{mM}$, Tris $\mathrm{PO}_{4}(\mathrm{pH} 7.4) 10 \mathrm{mM}, \mathrm{KCl} 5.0 \mathrm{mM}$, and $0.5-1.0 \mathrm{mg}$ mitochondrial protein. All measurements were at $20^{\circ}$. ADP/O ratios are expressed as micromoles of ADP added per microatom $\mathrm{O}_{2}$ consumed during the rapid state of respiration in the presence of ADP. Each result is the mean \pm SEM of 5-11 experiments at each age. ADP/O ratios are not included for experiments in which there was no clear state 3-4 transition (i.e., uncoupled). $P$ values, for the significance of the mean difference between results with matched litters, were calculated by the standard $t$-test for independent samples.

${ }^{2}$ Two of 11 experiments in series were uncoupled.

${ }^{3}$ One of seven experiments in series was uncoupled.

${ }^{4}$ Two of seven experiments in series were uncoupled.

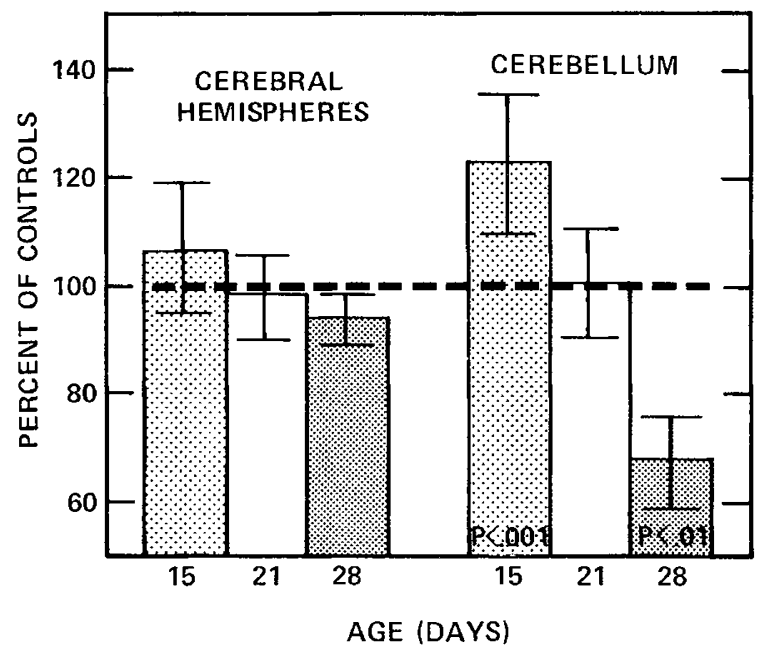

Fig. 1. Respiratory control ratios with oxidation of glutamate and malate in brain mitochondria from rats fed lead from 2 weeks of age. The reaction mixture and conditions are given in Table 2 . The results are the means \pm SEM of 7-12 experiments at each age expressed as a percentage of the results with simultaneously assayed mitochondria from age-matched control litters. $P$ values, for the significance of the mean difference between results with matched litters, were calculated by the standard $t$-test for nonindependent samples. 


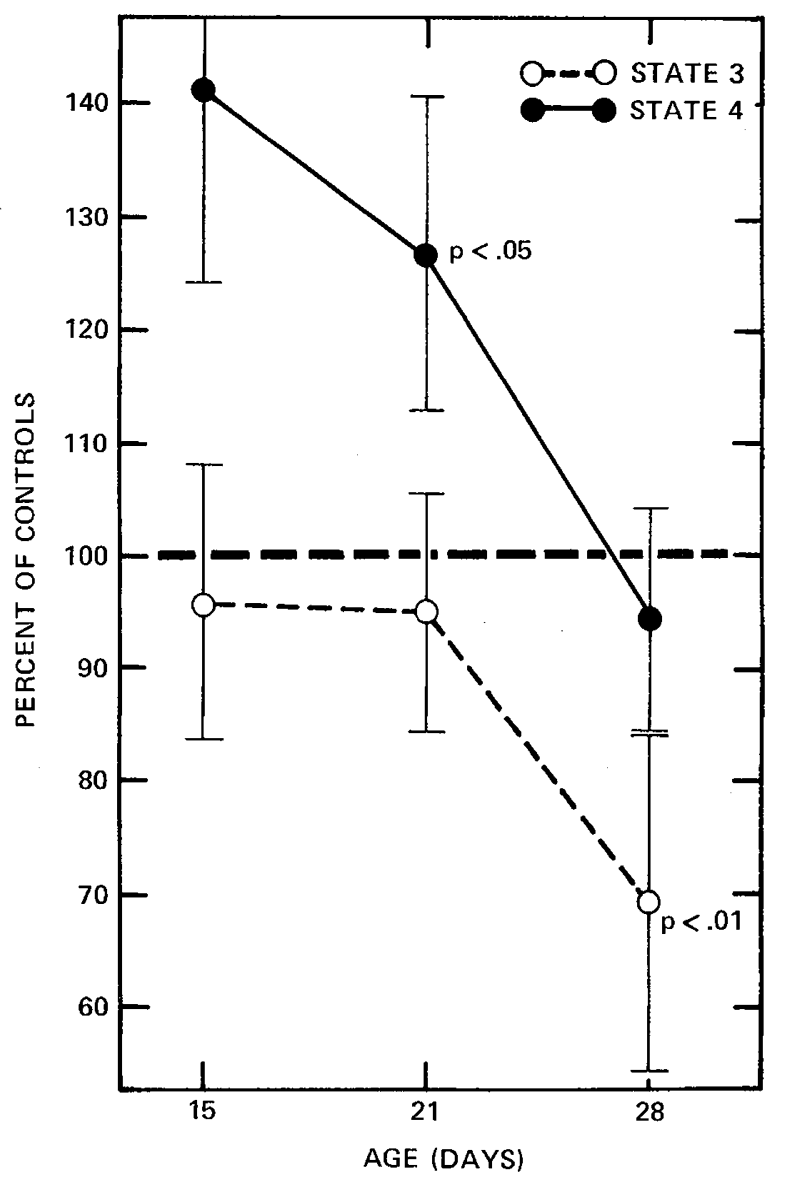

Fig. 2. State 3 and state 4 respiratory rates with oxidation of glutamate and malate in cerebellar mitochondria from rats fed lead from 2 weeks of age. The reaction mixture and conditions are given in Table 2. Respiratory rates were measured after adding ADP to the reaction mixture (state 3 ) and after consumption of the added ADP (state 4). The results are the means \pm SEM of 7-12 experiments at each age expressed as a percentage of the results with simultaneously assayed mitochondria from age-matched control litters. $P$ values, for the significance of the mean difference between results with matched litters, were calculated by the standard $t$-test for nonindependent samples.

mitochondria (17) was markedly attenuated in mitochondria from lead-fed animals.

Cytochrome oxidase activities in mitochondria from lead-fed and control animals are shown in Figure 3. The age-dependent increase in activity, reported in rat brain mitochondria during this period $(14,28)$, was seen in cerebral and cerebellar mitochondria from normal animals, but not lead-fed animals. Within 2 days of starting lead feedings, the cytochrome oxidase activity was significantly increased compared with controls in cerebellar mitochondria from lead-fed animals. With continued lead feedings, this activity progressively decreased, relative to controls, with the difference being significant after 2 weeks. Smaller changes, which were not significant, were observed in cerebral hemisphere mitochondrial cytochrome oxidase activity.

\section{DISCUSSION}

The effects of inorganic lead feedings on suckling rat brain mitochondrial respiration, both with NAD-linked substrates and with cytochrome oxidase activity, occurred in two phases temporally related to the onset of lead feedings. The early changes appeared in cerebellar mitochondrial respiration within 2 days of starting inorganic lead feedings to lactating mothers. With the NAD-linked substrate pair, glutamate and malate, there was a loss of dependence of respiration upon the presence of phosphate acceptor, shown by the increase in ADP-independent (state 4) respiration and the resulting decrease in control ratios. Cytochrome oxidase activity in cerebellar mitochondria was significantly increased within 2 days of lead feedings. This increased respiratory rate probably also reflected a release of respiratory control but control ratios could not be measured polarographically (30). With continued lead feedings, mitochondria from cerebellum and from cerebral hemispheres showed a progressive inhibition of ADP-dependent (state 3) respiration, control ratios, and ADP/O ratios with oxidation of the NAD-linked substrates. After 2 weeks of lead feedings, cytochrome oxidase activity was comparably decreased in cerebellar mitochondria. Thus, the effects of inorganic lead feedings were greater in cerebellar mitochondria, where there was, initially, a loss of respiratory control with little change in ADP/O ratios and, later, a decrease in both respiratory control and $\mathrm{ADP} / \mathrm{O}$ ratios with inhibition of ADP-dependent respiration.

These two phases of inorganic lead effects on mitochondrial respiration may be related to the increasing concentration of lead in the brain of the suckling rat during this period of feeding, as reported by Goldstein et al. (11). In the first week, when we observed only an uncoupling of controlled respiration in cerebellar mitochondria, there is little measurable increase in brain lead content. Lead concentrations rise sharply in both cerebellum and cerebrum in the second week of feedings, when we observed significant inhibition of coupled respiration in both regions. Assuming the tissue lead concentrations reflect the mitochondrial environment (3), inorganic lead may be acting like an uncoupling agent, such as dinitrophenol or dicoumarol. These agents cause a much greater drop in respiratory control than ADP/O ratios at low concentrations and inhibit respiration and oxidative phosphorylation at higher concentrations (4).

Inorganic and organic lead compounds produce similar concentration-dependent effects on mitochondrial respiration in mature brain and in other tissues. In mature rat brain and liver slices, organic lead compounds increase respiration at low concentrations and inhibit glucose and oxygen consumption at higher concentrations (2). If mature rats are fed inorganic lead for a period

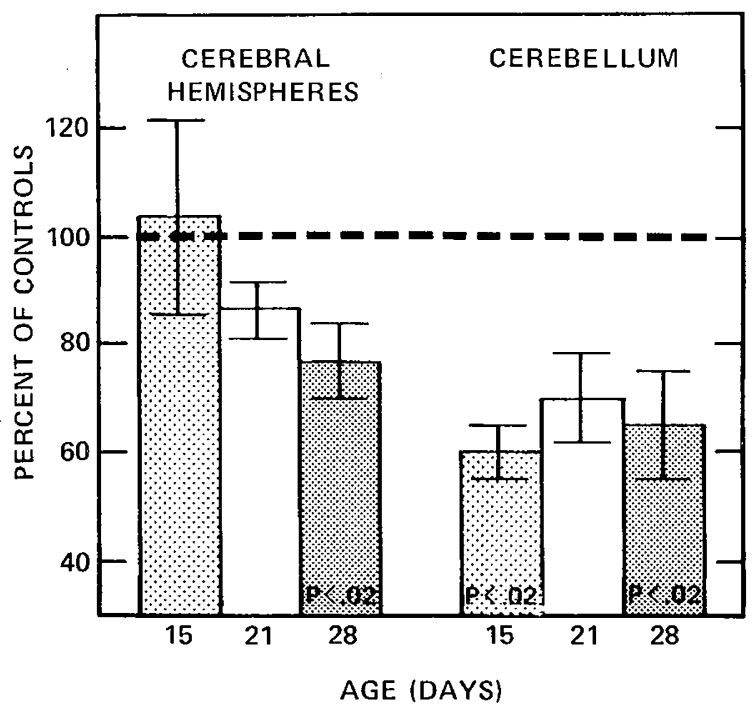

Fig. 3. Cytochrome oxidase activity in brain mitochondria from rats fed lead from 2 weeks of age. Respiratory rates were measured polarographically with oxidation of ascorbate $(1 \mathrm{mM})$ in the presence of tetramethyl$p$-phenylenediamine dihydrochloride $(100 \mu \mathrm{M})$, antimycin $\mathrm{A}(5 \mu \mathrm{g} / \mathrm{ml})$, and the reaction mixture described in Table 2 . All measurements were at $20^{\circ}$. The results are the means \pm SEM of $7-12$ experiments at each age expressed as a percentage of the results with simultaneously assayed mitochondria from age-matched control litters. $P$ values, for the significance of the mean difference between results with matched litters, were calculated by the standard $t$-test for nonindependent samples. 
sufficient to produce renal tubular swelling and amino aciduria, isolated renal cortical mitochondria show decreased respiratory rates, ADP/O ratios, and respiratory control with NAD-linked substrates (13). Similar inhibition of the respiratory chain occurs with in vitro exposure of rabbit renal cortical mitochondria to high concentrations of lead acetate (18), whereas lower concentrations of inorganic lead produce increased cytochrome oxidase activity in human placental mitochondria (8).

The loss in brain and body weights and the incidence of the hemorrhagic encephalopathy, which we observed, were comparable with these reported previously in suckling rats receiving inorganic lead by maternal feeding (21). A recent report suggests that the degree of weight loss and the severity of the encephalopathy may be causally related, since both are decreased if lead is fed directly to the pups (12). Brain lead concentrations are reportedly similar with the two methods of administration, but specific concentrations and ages of measurement are not stated (12). Malnutrition alone, during the suckling period, does not result in the encephalopathic changes observed with lead feedings (9). However, systemic effects, such as malnutrition and anemia, resulting from maternal lead feedings may enhance the pathologic sequelae or the biochemical effects of inorganic lead on the suckling rat brain.

The age at which the rat brain is sensitive to the encephalopathic effects of lead is relatively constant if lead feedings are begun any time in the first 2 weeks of life $(11,21,27)$. The critical period for exposure to lead appears to be the 3 rd and 4 th weeks of life. This is also a period of rapid increase in the activity and concentration of components of the rat brain mitochondrial respiratory chain (14, $16,17,28)$. The greater effects of lead on the cerebellum than the cerebrum, seen in morphologic studies $(6,11,27,32)$, as well as in our study of respiratory chain function, may be related, in part, to regional differences in mitochondrial respiratory chain function during this maturational period $(16,33)$. Differences in the effects of lead on cerebellar and cerebral hemispheres apparently are not due to differences in whole tissue lead concentrations, since, at the ages we have studied, the lead concentrations in these two regions are reportedly the same (11). The absence of encephalopathic effects of lead at older ages also may be related to the lower quantity of lead taken up by the mature brain (11).

We propose that the effects of inorganic lead on mitochondrial respiration, which appear more immediately after beginning feedings than any reported biochemical or morphologic effect on the rat cerebellum $(11,27,32)$, constitute an early step in the pathogenesis of an encephalopathy predominant in this region of the suckling rat brain. These effects, which we are reporting, may be part of, or may result in, a more general effect on glucose metabolism in the developing brain $(25,26)$. Pentschew and Garro (27) postulated that lead encephalopathy results from a deficiency of a necessary blood-born factor, in analogy with the pathologic effects of thiamine deficiency. We propose a similar hypothesis, that lead, as a blood-borne agent, produces a primary abnormality in oxidative energy metabolism in the immature brain. Whether the pathologic sequelae are the results of effects upon one cell population, such as the capillary endothelium (11), or due to a general metabolic dysfunction, we cannot say from this study. Our protocol, using high dose lead carbonate feedings, was designed to study the pathogenesis of a model for the clinically overt lead encephalopathy. Similar effects on respiratory chain function, with lower dose lead feedings, at developmental stages other than that which we have studied may be the basis for the teratogenic effects and changes in behavior and intelligence attributed to subclinical lead poisoning in the developing human (19).

\section{SUMMARY}

The effects of high dose inorganic lead feedings on brain mitochondrial respiration were studied in the suckling rat as an animal model for the pathogenesis of lead encephalopathy. Lead carbonate $(4 \%)$ was added to the diet of nursing rat mothers when litters were 2 weeks old. Cytochrome oxidase activity and oxidative phosphorylation with the substrate pair, glutamate and malate, were measured polarographically in isolated cerebral hemisphere and cerebellar mitochondria from experimental and control litters. Within 2 davs of beginning feedings, cerebellar mitochondria from lead-fed animals showed significantly lower respiratory control ratios with glutamate and malate oxidation, due primarily to an increase in the rate of ADP-independent respiration, compared with controls. Cytochrome oxidase activity was significantly increased in these mitochondria. During the subsequent 2 weeks, cerebellar mitochondria from lead-fed animals showed a progressive inhibition of ADP-dependent respiration and efficiency of oxidative phosphorylation (ADP/O ratio) and a comparable inhibition of cytochrome oxidase activity. Cerebral hemisphere mitochondria showed similar, but smaller, changes. The loss of respiratory control with glutamate and malate oxidation and the increased cytochrome oxidase activity in cerebellar mitochondria appeared earlier than any previously reported biochemical or morphologic effect of inorganic lead on the cerebellum. The effects on cerebellar respiratory energy metabolism may represent an early step in the pathogenesis of an encephalopathy which is predominant in this region of the developing rat brain.

\section{REFERENCES AND NOTES}

1. Adam, H.: Adenosine-5'-diphosphate and adenosine-5'-monophosphate. In: $\mathbf{H}$. U. Bergmeyer: Methods of Enzymatic Analysis, p. 573 (Academic Press, New York, 1965)

2. Aldridge, W. N., Cremer, J. E., and Threlafll, C. J.: Trialkyl-leads and oxidative phosphorylation: A study of the action of trialkylleads upon rat liver mitochondria and rat brain cortex slices. Biochem. Pharmacol., 11:835 (1962).

3. Baltrop, D., Barrett, A. J., and Dingle, J. T.: Subcellular distribution of lead in the rat. J. Lab. Clin. Med., 77: 705 (1971).

4. Chance, B.: Quantitative aspects of the control of oxygen utilization. In: G. E. W. Wolstenholme and C. M. O'Connor: Ciba Foundation Symposium on the Regulation of Cell Metabolism, p. 91 (Little, Brown, Boston, 1959).

5. Chance, B., and Williams, G. R.: A simple and rapid assay of oxidative phosphorylation. Nature, 175: 1120 (1955).

6. Clasen, R. A., Hartmann, J. F., Starr, A. J., Coogan, P. S., Pandolfi, S., Laing, I., Becker, R., and Hass, G. M.: Electron microscopic and chemical studies of the vascular changes and edema of lead encephalopathy. Amer. J. Pathol., 74: 215 (1974).

7. Croxton, F. E.: Elementary Statistics with Applications in Medicine and the Biological Sciences, p. 240 (Dover, New York, 1953).

8. Dawson, E. B., Cravy, W. D., Clark, R. R., and McGanity, W. J.: Effect of trace metals on placental metabolism. Amer. J. Obstet. Gynecol,, 103: 253 (1969).

9. Dobbing, J.: Undernutrition and the developing brain. In: W. A. Himwich: Developmental Neurobiology, p. 241 (Charles C Thomas, Publisher, Springfield, 1970).

10. Estabrook, R. W.: Mitochondrial respiratory control and the polarographic measurement of ADP/O ratios. Methods Enzymol., 10: 41 (1967).

11. Goldstein, G. W., Asbury, A. K., and Diamond, 1.: Pathogenesis of lead encephalopathy: Uptake of lead and reaction of brain capillaries. Arch. Neurol., 31: 382 (1974).

12. Golter, M., and Michaelson, I. A.: Growth, behavior, and brain catecholamines in lead-exposed neonatal rats: A reappraisal. Science, 187: 359 (1975).

13. Goyer, R. A., Krall, A., and Kimball, J. P.: The renal tubule in lead poisoning. II. In vitro studies of mitochondrial structure and function. Lab. Invest., 19: 78 (1968).

14. Gregson, N. A., and Williams, P. L.: A comparative study of brain and liver mitochondria from new-born and adult rats. J. Neurochem., 16: 617 (1969).

15. Holtzman, D., and Moore, C. L.: A micro-method for the study of oxidative phosphorylation. Biochim. Biophys. Acta, 234: (1971).

16. Holtzman, D., and Moore, C. L.: Oxidative phosphorylation in immature rat brain mitochondria. Biol. Neonate, 22: 230 (1973).

17. Holtzman, D., and Moore, C. L.: Respiration in immature rat brain mitochondria. J. Neurochem., 23: 1011 (1975).

18. Iannaccone, A., Boscolo, P., Bertoli, E., and Bombardieri, G.: In vitro effects of lead on enzymatic activities of rabbit kidney mitochondria. Experientia, 30: 467 (1974).

19. Lin-Fu, J. S.: Vulnerability of children to lead exposure and toxicity. N. Engl. J. Med., 289: 1229 (1973).

20. Lowry, O. H., Rosebrough, N. J., Farr, A. L., and Randall, R. J.: Protein measurement with the Folin phenol reagent J. Biol. Chem., 193: 265 (1951)

21. Michaelson, 1. A.: Effects of inorganic lead on RNA, DNA and protein content in the developing neonatal rat brain. Toxicol. Appl. Pharmacol., 26: 539 (1973).

22. Moore, C. L., and Jöbsis, F. F.: Some studies on the control of respiration in rat brain mitochondrial preparations. Arch. Biochem. Biophys., 138: 295 (1970).

23. Niklowitz, W. J., and Yaeger, D. W.: Interference of $\mathrm{Pb}$ with essential brain 
tissue $\mathrm{Cu}, \mathrm{Fe}$, and $\mathrm{Zn}$ as main determinant in experimental tetraethyllead encephalopathy. Life Sci., 13: 897 (1973).

24. Packer, L., and Jacobs, E. E.: Coupling of phosphorylation to terminal segments of the mitochondrial respiratory chain. Biochim. Biphys. Acta, 57: 371 (1962).

25. Patel, A. J., Michaelson, I. A., Cremer, J. E., and Balázs, R.: The metabolism of $\left[{ }^{14} \mathrm{C}\right]$ glucose by the brains of suckling rats intoxicated with inorganic lead. $\mathrm{J}$. Neurochem., 22: 581 (1974)

26. Patel, A. J., Michaelson, I. A., Cremer, J. E., and Balázs, R.: Changes within metabolic compartments in the brains of young rats ingesting lead. J Neurochem., 22: 591 (1974).

27. Pentschew, A., and Garro, F.: Lead encephalomyelopathy of the suckling rat and its implications on the porphyrinopathic nervous diseases. Acta Neuropathol., 6: 266 (1966)

28. Potter, V. R., Schneider, W. C., and Liebl, G. J.: Enzyme changes during growth and differentiation in the tissues of the newborn rat. Cancer Res., 5: 21 (1945).

29. Rhyne, B. C., and Goyer, R. A.: Cytochrome content of kidney mitochondria in experimental lead poisoning. Exp. Mol. Pathol., 14: 386 (1971).

30. Sanadi, D. R., and Jacobs, E. E.: Assay of oxidative phosphorylation at the cytochrome oxidase region (site III). 10:38 (1967).

31. Scott, K. M., Hwang, K. M., Jurkowitz, M., and Brierly, G. P.: Ion transport by heart mitochondria. XXIII. The effects of lead on mitochondrial reactions.

Copyright (c) 1976 International Pediatric Research Foundation, Inc.
Arch. Biochem. Biophys., 147: 557 (1971)

32. Thomas, J. A., and Thomas, I. M.: The pathogenesis of lead encephalopathy. Indian J. Med. Res., 62: 36 (1974).

33. Tyler, D. B., and Van Harreveld, A.: The respiration of the developing brain. Amer. J. Physiol., 136: 600 (1942).

34. Ralston Purina Co., St. Louis, Mo.

35. St. Louis, Mo.

36. Kanakee, III.

37. Phillipsburg, N. J.

38. Rochester, N. Y

39. San Diego, Calif

40. Ms. Emily Brewer is thanked for her technical assistance.

41. Dr. D. Holtzman is a Mellon Foundation Fellow.

42. These results were presented, in part, at the Sixth Meeting of the American Society for Neurochemistry.

43. This investigation was supported by a grant from the Research Development Fund of Stanford University.

44. Requests for reprints should be addressed to: D. Holtzman, M.D., Ph.D., Department of Neurology, Stanford University Medical Center, Stanford, Calif. 94305 (USA).

45. Accepted for publication September 16, 1975.

Printed in U.S.A.

Pediat. Res. 10: 75-78 (1976)

Cell-mediated immunity

inactivated vaccine lymphocyte transformation respiratory syncytial virus

\title{
Cell-mediated Immunity to Respiratory Syncytial Virus Induced by Inactivated Vaccine or by Infection
}

\author{
HYUN WHA KIM, SANFORD L. LEIKIN, JULITA ARROBIO, CARL D. BRANDT, \\ ROBERT M. CHANOCK, AND ROBERT H. PARROTT ${ }^{(13)}$ \\ George Washington University, Research Foundation of Children's Hospital Medical Center, Washington, D.C. and \\ Laboratory of Infectious Diseases, National Institute of Allergy and Infectious Diseases, National Institutes of \\ Health, Bethesda, Maryland, USA
}

\section{Extract}

Transformation and increased mitotic activity in donor lymphocytes exposed to specific antigens is considered by many to be a manifestation of cell-mediated immunity. In attempts to understand the apparent "sensitization" of individuals to respiratory syncytial virus (RSV) as a result of receiving inactivated RSV vaccine, in vitro lymphocyte transformation studies were carried out on infants who had received inactivated RSV vaccine and on infants who had received a similarly prepared inactivated African green monkey kidney (AGMK) cell-grown parainfluenza type 1 virus vaccine or a trivalent parainfluenza vaccine prepared in hen's eggs. Each group included some infants who had, and others who had not, undergone natural RSV infection under our observation before the lymphocyte studies.

Lymphocytes were studied from 21 infants and young children who had received the inactivated $\mathrm{RSV}$ vaccine, 14 who received a similarly prepared inactivated parainfluenza 1 vaccine, and 5 who received a trivalent parainfluenza vaccine. Twelve of the RSV vaccinees and 14 of the parainfluenza vaccinees had been naturally infected with RSV as indicated by virus recovery and/or antibody rise between the time of vaccination and the Iymphocyte studies. In comparing the arithmetic mean for RSV-specific transformation and mitotic activity there was a significant difference between RSV vaccinees and parainfluenza vaccinees whether one compared those who had undergone natural RSV infection or those who had not undergone natural infection. The difference between $\mathrm{RSV}$ vaccinees who had not undergone natural RSV infection and RSV-infected parainfluenza vaccinees also was significant. There was a greater level of transformation and mitotic activity in those who had experienced natural infection than those who had not among both RSV vaccinees and parainfluenza vaccinees, but these differences were not significant statistically.

\section{Speculation}

We take these findings to mean that natural RSV infection probably stimulates a systemic cell-mediated immunity response and that such a response is definitely induced after administration of killed RSV antigen. These findings are consistent with the hypothesis that cell-mediated sensitization may in some way contribute to the altered response to natural infection which occurred after use of inactivated RSV vaccine. Our findings do not support the hypothesis that systemic cell-mediated immunity per se is important in protecting against RSV infection. The findings also suggest the possibility that transplacentally conferred RSV lymphocyte sensitization might play a part in the pathogenesis of nonvaccine related RSV bronchiolitis which characteristically occurs during early infancy, frequently in the presence of measurable serum antibody.

The first potential vaccines against RSV in infants were inactivated virus preparations. One of these was a 100 times concentrated virus which had been grown in AGMK cell cultures 